\title{
Impairment, disability and handicap-old fashioned concepts?
}

R B Jones Retired Consultant Paediatrician, London

\begin{abstract}
The drawbacks of using the concepts of models in discussing the problems of disabled people are

discussed. It is suggested that the terms "impairment", "disability", and "handicap" can unify the different models and enhance the position of people with disabilities in society.

(Fournal of Medical Ethics 2001;27:377-379)
\end{abstract}

Keywords: Impairment; disability; handicap; medical model; social model

I read with interest the articles by Reindal and Harris since, although I accept that there is more to their papers than advocacy of models, they illustrate the dangers of the straitjacket approach to problems that using models represents. ${ }^{2}$ One side implies that if you are an advocate of the medical model you can't understand social impact, and the other that if you advocate the social model you must ignore physical impairment. I have recently retired from a professional life spent trying to provide services to disabled children, and in practice these mutually exclusive models do not work. Most of my patients did have physical impairments, which although rarely curable, did usually need treatment. These physical impairments often prevented them from carrying out actions, walking for example, with which their unimpaired peers had no problems. They were disabled. For many, society's response to their impairment and disability, inadequate education, rejection by their family or community for example, caused further problems; they were handicapped. The effect of social pressure on the response to disability can influence very strongly the wellbeing of the disabled person. For example, a child with a major chromosomal anomaly, was never acknowledged by the family. Her siblings were not allowed to play with her, and were not told that she was their sister. Her family belonged to a strict religious sect in which stigma attached to congenital abnormality such that it would have, for example, affected the marriageability of her siblings. At the age of four I lost contact with her and was told she had been placed in a long term residential institution. In effect, because of social pressure this family was denying, even within the immediate family that their own child was indeed a member of the family. It is interesting that Mundel found that in immigrant families, the mothers, when counting their children, often left out the disabled child as if he or she didn't exist. ${ }^{3}$

Although it is old-fashioned, I wish to suggest that the use of the three terms, impairment, disability, and handicap, unites the various models and is of practical value. The definitions of these words that I will start with are those of the original World Health Organization (WHO) classification ${ }^{4}$ rather than the recent updated version of it, because although this claims to be aimed at uniting the medical and social models, in my opinion it does not sufficiently differentiate between, for example, poor air quality affecting breathing and poor attitudes to disability such as described above which affect the life of disabled people ${ }^{5}$ : Impairment: any loss or abnormality of psychological, physiological, or anatomical structure or function. Disability: any restriction or lack (resulting from an impairment) of ability to perform an activity in the manner or within the range considered normal for a human being. Handicap: a disadvantage for a given individual, resulting from an impairment or a disability, that limits or prevents the fulfilment of a role that is normal (depending on age, sex, and social and cultural factors) for that individual.

It is clear, however, that these definitions are not in themselves adequate and need modification.

Superficially, the word impairment seems to need least modification, but even this is to some extent culturally determined. What is seen in one society as an impairment may appear beneficial in another. There is, for example, a South American tribe in which dyschromic spirochaetosis, which induces coloured skin lesions, is almost universal, so that these are regarded as so desirable that those few members of the tribe who escape the infection are unable to obtain marriage partners. ${ }^{6}$ If caught by a stranger, it would be a disfiguring impairment. This is also well illustrated in fiction, in The Country of the Blind, by $\mathrm{H} \mathrm{G}$ Wells. ${ }^{7}$ In this story, a mountaineer stumbles into an isolated valley, all of whose inhabitants are anophthalmic, and although he is sighted, he is so clumsy that he cannot function in that society. It also illustrates the dangers of latching onto the wrong impairment. 
The people of the valley do not understand that it is his senses other than sight which are at fault, but assume that his impairment is that he is different from them - he has eyes. The cure for his impairment is therefore simple: remove his eyes. "And then he will be sane? Then he will be sane, and a quite admirable citizen". ${ }^{8}$

As I have argued elsewhere, ${ }^{9}$ this sort of disastrous error in defining the impairment is not confined to fiction. By defining the facial appearance of a child with Down's syndrome as the primary impairment, major and unjustified surgery is performed to "cure" it. There are two different things being said here. In the Wells example, if one considers the human species as a whole then it is the valley inhabitants who are impaired; they do not possess eyes that are the norm for the species. The mountaineer's impairment is his poorly developed other senses. By focusing on the physical: by, so to say, adopting the medical model, the valley people get the diagnosis and therefore the treatment wrong. On the other hand the characteristic facial appearance of Down's syndrome could be seen as an impairment, a variation from the norm for the species. Plastic surgery will in no way "cure" the Down's syndrome. It will not, for example, increase intellectual function nor reduce the susceptibility to developing leukaemia. What it will do is make it less easy to recognise that the person has the syndrome and therefore, hopefully, lessen adverse social response to him.

Even given these limitations, however, it is usually possible to define the loss of function, the impairment. Is impairment always disabling or handicapping? Both Harris and Reindal use achondroplasia as an example, Harris claiming that it is not a disability. There is, however, an impairment; there is failure of growth in the long bones. Harris claims, however, that this is rarely disabling, and, in present day Britain, rarely handicapping. This view is not shared by Shakespeare, a sociologist who has achondroplasia. His view is that a disabled person is one who feels himself to be disabled ("No Triumph, No Tragedy", BBC Radio 4 , Jun 2000). This view intimately links the three words since, particularly in the case of something like restricted growth, whether the person with it regards the impairment as disabling will be coloured by the handicapping effect of society's response to it.

To return to the two examples of the sighted mountaineer and the Down's syndrome child. Since attitudinal change is never achieved overnight could it be claimed that to render them normal by the prevailing criteria of their community would be of benefit to them? To remove the mountaineer's eyes would, superficially, make him the same as the other inhabitants of the valley and ease his marriage to the chief's daughter. On the social level, however, by removing the only acute sense that he has, it would render him totally helpless, rather than just clumsy. In no way would it improve him, or for that matter the attitude of the valley inhabitants towards him; it would confirm their belief that he was a lesser being. The Down's syndrome example is less clear cut, since opinion is divided on whether the characteristic facial appearance is indeed of prime importance in defining the attitude of society to Down's syndrome. Olbrisch, a plastic surgeon contends that "although mental retardation is the most critical of all the disabilities in Down's syndrome, it is the facial appearance which provides the barrier between the child and his acceptance in society", and that corrective surgery does indeed improve society's response, since, before the child is operated on "many change their attitude to the child in the mistaken belief that it must be an imbecile because it looks like one". ${ }^{10}$ On the other hand, Pueschel et al, found that, based on a questionnaire given to the parents of Down's syndrome children, $83 \%$ felt their children were well accepted by society. ${ }^{11} \mathrm{Be}$ that as it may, major surgery is not being performed in order to improve function in the individual, but to improve other peoples' response to him. In a recent television programme ("Changing Faces", Carlton Television, Nov 1998), there was no doubt that the adult patient interviewed felt he had benefited greatly from the surgery. On the other hand, a very young baby, incapable of giving consent, was subjected to major surgery, and cut off from contact with his parents by it, at a crucial time in the development of bonding and of commnication. In my opinion unless the person involved is able to give fully informed consent, then the damage outweighs the benefit

The definition of disability is more problematic since it uses the value-laden term normal. Clearly if this is being used statistically, then in H G Wells's valley to be without eyes is normal and to have eyes abnormal. Boorse attempts to overcome this problem, albeit when discussing disease and illness rather than disability, by suggesting that "the single unifying property of all recognised diseases . . . appears to be this: that they interfere with one or more functions typically performed within members of the species", and that what would make the anophthalmia abnormal is that it is "unnatural ... by being atypical [for the species]". ${ }^{12}$

This is in itself not a satisfactory answer, since what is typical or atypical for the species may itself be culturally determined in some instances. For example, an impairment which prevents walking presumably causes disability in any society, but one which results in dyslexia will only cause disability in a literate society, since even if it is claimed that the skill, to be able to read for example, is innate in all humans, in a society that does not utilise this skill inability to read will be masked. In this respect the WHO definition of disability, in relating it to the whole species, rather than to specific communities as it does with handicap, is too wide.

The definition of handicap is particularly problematic and is perhaps the least useful of the three since it is often felt to be discriminatory in itself, with the suggestion that it derives from "cap in hand", implying that disabled people are expected to beg favours of the able. A dictionary definition, however, suggests a different derivation, from 
"hand i' cap", a form of sporting lottery. ${ }^{13}$ The suggestion here is that in the same way that the sporting community imposes a burden on some golfers or horses, the general community imposes a burden on some of its members. It should be noted, however, that, whereas the former is aimed at making things fairer, the latter definitely is not. It also implies that handicap, like impairment, is intrinsic to the individual, whereas in the main, it is the response of the able community to those with impairments and disabilities that is the main source of handicap. I still remember attending a conference at the outset of my career, held at a major teaching hospital, on facilities for the disabled, at which the wheelchair-bound main speaker had to be manhandled onto the stage because there was no other access. Thirty years later, the situation is unchanged. In some countries, Germany for example, laws are still being passed to restrict people with disabilities. Recent decisions in Germany have for example, required disabled people in a community home to remain indoors except during specific times, because their behaviour might offend the neighbours, and banned disabled people from holiday resorts because their presence would lower the prices that could be charged for holidays. ${ }^{14}$

What then are the uses of these three terms? In using the term impairment, recognition is given to the fact that disabled people do often have a physical substrate to their disability. There is, if you like, a medical aspect to it, which if recognised, may result in treatment which may ameliorate the problem. Despite the definite presence of an impairment, treatment is not always necessary and can in fact be detrimental. Sacks for example, comments on a patient with temporal lobe epilepsy manifested by reminiscence of a forgotten childhood which was, in his words, healing, for that person. She herself refused treatment of the epilepsy in order not to be deprived of the reminiscences. ${ }^{1}$

The term disability also recognises an important fact; disability can cause disadvantage, which again can, if recognised, be ameliorated by modification of the environment in which the person lives.

Handicap, as has already been noted is the most difficult term to use, because, in a sense, it has nothing to do with the disabled person. It is the impairment rampant in the rest of us, the inability to overcome our own prejudices, which ensures that any disadvantage resulting from impairment or disability is magnified.

In the recent revision of the WHO classification, ${ }^{16}$ an attempt is made to unite the two models. Impairment and disability as defined above are combined in the word disability, and a separate classification of environmental factors covering the barriers to the integration of disabled people created by societal attitudes replaces the concept of handicap. Should we therefore abandon the word handicap as the WHO have done? In my view we should not. In the new system insufficient differentiation is made between environmental factors which influence function, such as air quality affecting breathing, and attitudinal factors which magnify the problems of adjustment that disabled people have. In this way it can be claimed that, in that I am not personally responsible for air quality, I cannot be held responsible for attitudes which lead to objecting to, say, sheltered accommodation for disabled people in my street either. By retaining the word handicap, defined as I have above, as an impairment in the attitude to disability in others of individual members of society, this confusion does not occur. What is positive about the new classification is that the WHO are suggesting, as I am, that we abandon models which seem to be geared to ensuring that our own disciplinemedicine, education, sociology or whatevercomes out on top in the debate, and take a truly holistic view of the problems encountered by people with disabilities, working together with them to ensure that they have equality of opportunity within the community.

$R$ B fones, PhD, FRCP, FRCOphth, FRCPCH, is a retired Consultant Paediatrician.

\section{References}

1 Reindal SM. Disability, gene therapy and eugenics-a challenge to John Harris. Fournal of Medical Ethics 2000;26:89-94.

2 Harris J. Is there a coherent social conception of disability? fournal of Medical Ethics 2000;26:95-100.

3 Mundel G. The old beliefs and the cerebral palsied. Rehabilitation Record 1968;9:16-21.

4 World Health Organization. International classification of impairments, disabilities and handicaps. Geneva: WHO, 1980.

5 World Health Organization. International classification of functioning, disability and health. Geneva: WHO, 2000: 27-9

6 Hare RM. Health. Fournal of Medical Ethics 1986;12:174-81.

7 Wells HG. The country of the blind. Reprinted in: Dolley C, ed. The Penguin book of English short stories. Harmondsworth: Penguin, 1967: 103-28

8 See reference $7: 124$

9 Jones RB. Point of view: Parental consent to cosmetic facial surgery in Down's syndrome. Fournal of Medical Ethics 2000;26:101-2.

10 Olbrisch RR. Plastic surgical management of children with Down Syndrome: indications and results. British fournal of Down Syndrome. indications

11 Pueschel SM, Monteiro LA, Ericson M. Parents' and physicians' perception of facial plastic surgery in children with Down syndrome. Fournal of Mental Deficiency Research

12 Boorse C. On the distinction between disease and illness. In: Cohen M, Nagel T, Scanlon T, eds. Medicine and moral philosophy. Princeton, NJ: Princeton University Press, 1981: 11-13.

3 Sykes JB, ed. The concise Oxford dictionary of current English [6th ed]. Oxford: Oxford University Press, 1976.

14 Anonymous [editorial]. Ausgrenzung von Behinderten. (Excluding the disabled) Pflege Zeitschrift 1998;51:176.

15 Sacks O. The man who mistook his wife for a hat. London: Picador, 1986: 137.

16 World Health Organization. International classification of functioning, disability and health. Geneva: WHO, 2000. 